\title{
PEPETELA. O CÃO E OS CALUANDAS. SÃO PAULO: KAPULANA, 2019.
}

\author{
Larissa Costa da Mata
}

Pós-Doutoranda em Literatura Brasileira pela Universidade de São Paulo.

Via Atlântica, Săo Paulo, n. 38, pp. 425-436, dez. 2020. 
Em 2019, a editora Kapulana publicou o romance $O$ cão e os caluandas do escritor angolano Pepetela que, embora seja originalmente de 1984, ganha pela primeira vez edição no Brasil, com apresentação de Tânia Macedo. Ainda que a literatura africana de língua portuguesa apresente um intenso diálogo com a brasileira, com a exceção de autores como Mia Couto, os escritores dessas nações ainda não são devidamente lidos pelos nossos, bem como pelo público leitor em geral. Desse modo, a Kapulana parece ocupar parte desse hiato no mercado editorial nacional, facilitando a difusão de Pepetela e de outros escritores de Angola e Moçambique no país. $O$ cão e os caluandas é o primeiro do autor impresso pela editora, que também nos trouxe Sua excelência de corpo presente (2020) e $O$ quase fim do mundo (2020). Como veremos, o romance revela uma concepção de linguagem como gesto que instaura a diferença de alteridades. Por outro lado, a heterogeneidade da linguagem e da estrutura do texto, constituído por depoimentos e documentos aparentes, conduz a proximidade entre a literatura e a pós-memória, a ficção e o arquivo.

Pepetela (Artur Carlos Maurício Pestana) esteve vinculado ao Movimento Popular de Libertação de Angola e participou da guerra pela independência do país (1961-1974). Os seus primeiros livros, como Ana Mafalda Leite (2003), Igor Cusack (2009) e Rita Chaves (1999) destacaram, pertenceriam a uma fase de escritos sobre a luta revolucionária angolana e à 
tentativa de reconstituição da história do país que emergia. Esse seria o caso, por exemplo, de Mayombe (1980), em que esboça uma épica da luta guerrilheira pela libertação, e de Lueji (1989), no qual se interessa pelos documentos que traz à matéria ficcional, fazendo uma mescla entre os registros da história e a verossimilhança, ao se valer de um mito nacional de origem, o da rainha Lunda, forjando o nascimento de um império.

Por outro lado, a literatura angolana (e a africana de língua portuguesa) vem sendo analisada em virtude do que Rita Chaves (2004) designou como a transformação de uma "imperícia linguística" em virtude literária. Ou seja, a língua oficial portuguesa, legada pela metrópole, é subvertida quando atravessada pelos idiomas nativos, fazendo-se, ademais, uma aproximação semântica, lexical e sintática das poéticas populares e dos registros orais e escritos.

Em Angola, podemos mencionar dois casos emblemáticos nesse sentido, o de Pepetela e o de José Luandino Vieira (pseudônimo de José Vieira Mateus da Graça). Os contos que o último publicou em Luuanda (1964) se compõem de neologismos e de empréstimos das línguas bantus como o quimbundo, além de provérbios, que despontam um gesto de resistência simbólico por meio do idioma das minorias étnicas. Isso se nota desde a epígrafe do livro, a qual afirma, em quimbundo, que "Nessa nossa terra de Luuanda passam coisas que envergonham" (VIEIRA, 2004), e 
em diversos registros que misturam o português normativo à linguagem oral e ao quimbundo.

$O$ cão e os caluandas reúne os depoimentos de personagens que funcionam à semelhança de tipos um poeta revolucionário, um oficial, uma prostituta, atores de teatro -, que partilharam o encontro com um cão pastor-alemão andarilho. 0 texto assume ares polifônicos, os quais refletem a pluralidade étnica de Angola, segundo vemos no capítulo "Luanda, assim nossa":

[...] Desde que o colono bazou, passou ainda pouco tempo. Mas como querem que se ponha esta Babilônia em ordem se aqui vivem malanjinos, ilhéus, ambakas, umbundos, quiocos e até mesmo mulatos? Dos brancos já nem se fala, é uma confusão e brancos de vários cambiantes, angolanos (dizem!), suecos, franceses, soviéticos, brasileiros, cubanos, portugueses... Uns mais rosados, outros mais tisnados... E sem falar nos kilongos que sonham tornar Luanda na nova capital do novo Reino do Kongo [...]. E os lingalas então, os recentíssimos angolanos? Isto é uma Babilônia ingovernável, uma Torre de Babel. (PEPETELA, 2019, p. 36)

0 caráter heterogêneo do texto se instaura, como em Luuanda, pela mescla entre os registros oficiais da língua portuguesa e a oralidade, bem como pela recriação do idioma europeu, combinando-o às marcas das línguas nativas de Angola como o quimbundo: "a kasukuta provocada pelo cão"; "as puítas, as dicanzas, os kissanjes, misturados aos búzios" (PEPETELA, 2019 , p. 89) etc. Desse modo, o livro conta com um 
glossário que esclarece ao leitor quanto aos sentidos produzidos por essa linguagem híbrida, que combina, aparentemente, os registros de "um inquérito rigoroso, muitas solas gastas, a procurar pessoas e, sobretudo, convencê-las falar, a escrever, ou a darem-me na candonga fotocópias de documentos" (PEPETELA, 2019, p. 15).

De acordo com o teórico indiano Homi Bhabha, em O local da cultura (2001), no texto pós-colonial, o sujeito desaparecido coloca o "eu" no lugar de domínio, enquanto ausência e representação. Esse sujeito retorna como um terceiro elemento, que não é puramente o "eu" do colonizador nem o "outro" colonizado, mas a própria distância que permanece entre eles. À guisa de ilustração, Bhabha menciona a evangelização inglesa nas colônias africanas e asiáticas, na qual os livros europeus sagrados e literários operavam como uma escritura metafórica do Ocidente e revelavam a visão normalizadora da colonização europeia, bem como uma imagem arcaica da identidade. Ao mesmo tempo, uma transfiguração significativa do discurso do colonizado resultaria dos livros, produzindo a différance no seu interior. Desse modo, os indianos conseguiram imprimir marcas da cultura nativa na da metrópole, impedindo que se consolidassem os processos de imposição irrestrita da cultura hegemônica e de homogeneização.

Embora seja inegável que haja um vínculo com o contexto de formação de Angola como país autôno- 
mo, o romance de Pepetela ultrapassa as hipóteses de afirmação identitária, podendo ser lido como um texto híbrido que reflete a existência de um terceiro elemento, que não é nem o estrangeiro, nem o autóctone. A Angola que figura nesse texto, especificamente a cidade de Luanda, se aproxima muito mais dessa comunidade da diferença apontada por Bhabha, ou mesmo de uma comunidade confrontada, em que seres singulares-plurais estabelecem diálogos entre si, do que de um todo homogêneo, em que um grupo único procura assegurar a unidade da nação. Assim, essas diversas faces de sujeitos e comunidades se apresentam no texto por meio dos seus gestos de resistência, como aquele da linguagem, perpetuando a singularidade no conjunto de etnias distintas.

Em "Entre judeus", um aspirante a escritor se depara com uma prostituta e relata o evento no conto que será, depois, ofertado ao autor-suposto do romance. Na conversa entre ambos, surge uma comparação entre o mulato e o judeu que não deixa de ser ilustrativa daquilo que Bhabha mencionou como o "terceiro elemento" do pós-colonialismo. Se, no romance, o mulato também figura como um sujeito cuja cor da pele pode lhe conferir privilégios ${ }^{1}$, ele também

1 Nesse sentido, traz um argumento similar ao de Delfina, de $O$ canto alegre das perdizes (2008), da moçambicana Paulina Chiziane, quem sugere que fazer filhos mulatos - como lhe aconselhara a sua mãe - seria uma forma de "melhorar a cor da pele" e ascender socialmente. 
é um sujeito híbrido, que não pertenceria a tribo nenhuma:

[...] Mulato é o judeu de Angola. Ouvi isso dum amigo poeta e gostei da ideia. Mulato-judeu-de-Angola! Os judeus sempre foram os tipos que levaram a todos. Aqui é o mulato. Se alguma coisa corre mal, a culpa é do mulato que estiver mais perto. Porque os negros têm a sua tribo. Melhor, a sua tribo é a dos mulatos... [...] (PEPETELA, 2019, p. 128)

O mulato, o "judeu-de-Angola", seria, portanto, um "eu" que nem é propriamente o branco opressor, nem o nativo intocado pela colonização, pois se encontra numa posição intersticial e se assemelha ao judeu, visto que ambos teriam uma identidade sempre fugidia e sofreram a opressão histórica. Ele se aparenta, ainda, a uma sorte de bode-expiatório, cuja imagem o equipara tanto aos povos autóctones quanto ao branco colonizador. Por conseguinte, expia a culpa de um pelos feitos atrozes, e o ódio do outro, provocado pela brutalidade que o afligiu, assim como o Judas Ahsverus de Euclides da Cunha (1986).

Essa linguagem híbrida, em $O$ cão e os caluandas, que é gesto de resistência e mímica de sujeitos diversos, vincula, igualmente, esse texto a tempos outros, a literatura ao arquivo e à pós-memória. Como o autorsuposto enfatiza, a voz que fala, no texto, ecoa do passado, "[...] da época em que aconteceram os casos" (PEPETELA, 2019, p. 15). 0 "inquérito rigoroso" cons- 
tituído pelo relato costura os diversos depoimentos dos moradores de Luanda sobre o encontro com o cão Lucapo, alguns deles orais, em forma de conto (como o da prostituta) e, outros, em fragmentos-capítulos que simulam documentos: atas de reuniões, notícias de jornais, relatórios, páginas de diário íntimo e uma carta destinada ao "camarada escritor". Desse modo, o texto confronta a literatura e o arquivo, ou seja, os elementos de recalque da história tradicional. Nesses termos, quando esses simulacros de documentos se associam aos depoimentos dos moradores de Luanda, também ficcionais, o romance assume o caráter de um testemunho que, se não serve de suplemento ao discurso histórico, colabora para apontar as suas lacunas.

Nas constantes interpelações do autor ao leitor, que perpetuam o jogo da mentira romanesca, à semelhança da ficção de Laurence Sterne, Machado de Assis $^{2}$ ou Almeida Garrett, $O$ cão e os caluandas constantemente evoca a sobreposição da estória à história. Essas interferências se dão por meio dos apelos dos "narradores em primeiro grau" ao escritor, buscando atestar a veracidade dos fatos e solicitando que as suas falas sejam registradas ipsis litteris, segundo o Poeta Tico: "Pode agora escrever, mas igualito contei.

2 Vale mencionar que um dos romances de Pepetela, publicado pela editora Kapulana neste ano, Sua excelência de corpo presente (cuja primeira edição, portuguesa, é de 2018), se vale de um "autor-defunto", como Machado de Assis em Memórias póstumas de Brás Cubas: um ditador africano, morto, que tece reflexões em seu próprio velório. 
Igualito" (PEPETELA, 2019, p. 21). 0 autor-suposto justapõe os trechos relatados pelos diversos interlocutores, ao mesmo tempo em que intervém com a sua presença, assumindo posições e saindo "de trás das trincheiras"; confessando criar "versões" do que vira ou escutara. Ironicamente, quando declara o seu capricho, no capítulo “Carnaval com Kianda”, refutando, assim, a veracidade, aproxima o seu texto - ficcional - do discurso da História, factual:

[...] Mas desde já aviso qual a maka do historiador: a sua versão pode estar completamente errada, mas vai sempre influenciar no futuro qualquer análise sobre os acontecimentos que narra. Já o Heródoto sabia ao enfiar as suas kíbuas que até hoje continuamos a engolir (PEPETELA, 2019, p. 85)

A compilação das estórias daqueles que experimentaram os eventos combina o discurso da memória (pois se preocupa em capturar experiências diretas, "vividas" pelo narrador) e o da pós-memória, ou seja, o das experiências alheias, reelaboradas pela escuta das vozes de sujeitos que testemunharam diretamente os acontecimentos, de acordo com Beatriz Sarlo (2007). O que é fundamental é que, seja pela mediação das lembranças de alguém por um indivíduo distinto, seja pelo caráter de centralização em um sujeito, cuja imparcialidade é falha, os dois discursos não podem ser confundidos com a factualidade histó- 
rica, pois se remetem aos interditos e aos limites da representação pela linguagem.

Associados às narrativas dos filhos dos desaparecidos das ditaduras latino-americanas e dos sobreviventes dos campos de concentração pela teoria literária, o testemunho e a pós-memória, na literatura pós-colonial de língua portuguesa, dá voz e denuncia a penúria vivida pelo sujeito mestiço nos países africanos recém-libertos. Isso se revela na peça de teatro, cuja leitura é transmitida pela rádio, em "Elogio da ignorância", em que a educação formal se associa aos privilégios burgueses. Igualmente, na perpetuação do analfabetismo mesmo em indivíduos que atingiram algum grau de ascensão social, como o pai da dona do cão Lucapa, bem como na marginalidade que assola os "regressados", angolanos haviam se exilado no Zaire para fugir da guerra de libertação e que retornam ao país com dificuldade de se reinserirem na sociedade.

Assim, O cão e os caluandas assinala uma proximidade com uma série de textos ficcionais da contemporaneidade, dos países africanos, europeus e latino-americanos que dão voz aos discursos silenciados pela História, daqueles que foram subjugados pela violência, como ocorrera nos regimes totalitários, durante as guerras de libertação ou nas colônias recém-libertas, nas quais os nativos permaneceram, embora incluídos no território, na condição de párias, de judeus-mulatos. Ademais, evoca a presença desse 
terceiro elemento, que nem pode conservar a pureza identitária, anterior à presença europeia, nem pode refutar propriamente a linguagem do colonizador. Por isso, se vale da língua portuguesa e a torna "fala impura", subvertendo os mecanismos de poder que, mesmo no pós-colonialismo, herdaram a tentativa de instaurar uma nação homogênea, legando à marginalidade os falantes dos idiomas nativos (MATA, 2019).

\section{Referências}

BAHABHA, Homi K. O local da cultura. Tradução de Myriam Ávila, Eliana Lourenço de Lima Reis e Gláucia Renate Gonçalves. Belo Horizonte: UFMG, 2001.

CHAVES, Rita. Pepetela: romance e utopia na história de Angola. Via Atlântica/USP, São Paulo, n. 2, jul. 1999.

CHAVES, Rita. 0 passado presente na Literatura Africana. Via Atlântica/USP, São Paulo, n. 7, p. 146-161, out. 2004.

CHIZIANE, Paulina. $O$ canto alegre das perdizes. Alfragide-PT: Caminho, 2012.

CUNHA, Euclides. Um paraíso perdido: ensaios, estudos e pronunciamentos sobre a Amazônia. Organização de Leandro Tocantins. Rio de Janeiro: José Olympio, 1986.

CUSACK, Igor. Performance and the Mobilization of Identity in Pepetela's Lueji: O Nascimento de um Império. Portuguese Studies, Cambridge, v. 25, n. 2, p. 169-181, 2009.

LEITE, Ana Mafalda. As literaturas africanas e formulações pós-coloniais. Lisboa: Colibri, 2003.

MATA, Inocência. Epistemologias do "colonial" e da descolonização linguística: uma reflexão a partir de África. Gragoatá, Niterói, v. 24, n. 48, p. 208-226, jan.-abr. 2019.

PEPETELA. Mayombe. Rio Tinto: ASA, 1989.

PEPETELA. $O$ cão e os caluandas. São Paulo: Kapulana, 2019. 
PEPETELA. Lueji: o renascimento de um império. Lisboa: Dom Quixote, 2003.

PEPETELA. Sua excelência de corpo presente. São Paulo: Kapulana, 2020a.

PEPETELA. $O$ quase fim do mundo. São Paulo: Kapulana, 2020b.

SARLO, Beatriz. Tempo passado: cultura da memória e guinada subjetiva. Tradução de Rosa Freire d'Aguiar. Belo Horizonte: UFMG; São Paulo: Companhia das Letras, 2007. VIEIRA, José Luandino. Luuanda. Luanda: Mzila, 2004. 